\title{
BMJ Open Prescribing trends over time by non- medical independent prescribers in primary care settings across Wales (2011-2018): a secondary database analysis
}

Saeed Saad A Alghamdi (D) , ${ }^{1}$ Karen Hodson, ${ }^{1}$ Paul Deslandes, ${ }^{2,3}$ David Gillespie, ${ }^{4}$ Kath Haines, ${ }^{2}$ Elliott Hulme, ${ }^{1}$ Molly Courtenay, ${ }^{5}$ Rhian Deslandes ${ }^{1}$

To cite: Alghamdi SSA, Hodson K, Deslandes P, et al. Prescribing trends over time by non-medical independent prescribers in primary care settings across Wales (20112018): a secondary database analysis. BMJ Open 2020;10:e036379. doi:10.1136/ bmjopen-2019-036379

- Prepublication history and supplemental materials for this paper is available online. To view these files, please visit the journal online (http://dx.doi. org/10.1136/bmjopen-2019036379).

Received 17 December 2019 Revised 08 August 2020 Accepted 04 September 2020

Check for updates

(c) Author(s) (or their employer(s)) 2020. Re-use permitted under CC BY-NC. No commercial re-use. See rights and permissions. Published by BMJ.

For numbered affiliations see end of article.

Correspondence to Saeed Saad A Alghamdi; alghamdiss@cardiff.ac.uk

\section{ABSTRACT}

Introduction As of 2015, as part of the implementation of the Welsh Government primary care plan and primary care clusters, the Welsh Government has encouraged nonmedical healthcare professionals working in primary care to train as independent prescribers (IPs).

Objectives This research aimed to identify the number of NMIPs in primary care in Wales and describe their prescribing trend of items between 2011 and 2018, in order to compare their prescribing pattern before and after the implementation of primary care clusters for Wales. Design Retrospective secondary data analysis and interrupted time series analysis in order to compare prescribing by non-medical independent prescribers (NMIPs) preimplementation and postimplementation of primary care clusters across Wales.

Results Over the study period, 600 NMIPs (nurses $n=474$ and pharmacists $n=104$ ) had prescribed at least one item. The number of nurse IPs increased by $108 \%$ and pharmacists by $325 \%$ (pharmacists had the largest increase between July 2015 and March 2018). The number of items prescribed by NMIPs increased over time by an average of 1380 per month $(95 \% \mathrm{Cl} 904$ to $1855, p<0.001)$ after the implementation of primary care clusters compared with 496 ( $95 \% \mathrm{Cl} 445$ to $548, \mathrm{p}<0.001)$ prior its implementation. Approximately one-third of the items prescribed by NMIPs was within Betsi Cadwaladr University Health Board (HB) with only 4\% in Powys Teaching HB.

Conclusion The number of NMIPs and their volume of prescribing in primary care in Wales has increased following the implementation of primary care clusters in 2015. This suggests that the Government's recommendations of using NMIPs in primary care have been implemented. Future studies should focus on efficiency and quality of prescribing by NMIPs in primary care.

\section{INTRODUCTION}

The right to prescribe medicines was traditionally restricted to physicians, dentists and veterinary surgeons. ${ }^{1}$ Prescribing practice has
Strengths and limitations of this study

- This is the first study using a secondary database analysis, which has provided insights and empirical findings on the prescribing pattern of medicines by non-medical independent prescribers (NMIPs) over time in primary care in Wales.

- The data provided via the Comparative Analysis System for Prescribing Audit (CASPA) software system was limited to the last 7 years and only captured prescriptions that were dispensed in community pharmacies.

- The CASPA system was designed for financial reimbursement purposes for community pharmacies, which means that holding investigations at the level of patients or prescribers, such as stopping or changing patients' medications, as well as clinical safety issues or other prescribing activities, were not possible.

- The professions of NMIPs as pharmacist, nurse, physiotherapist or others were not identified on the prescriptions and, consequently, in the CASPA system.

- The interrupted time series analysis has the strength of evaluating data at the whole population level, which allowed the researchers to evaluate the utilisation of NMIPs in primary care across all of Wales.

changed over the last 50 years to involve physicians and dentists (medical prescribers) and other healthcare professionals, known as nonmedical prescribers. The adoption of nonmedical prescribing fundamentally began in the USA in the $1960 \mathrm{~s}^{2}$ and has extended to the UK, Canada, New Zealand, Australia and other European and African nations. ${ }^{3}$ Beyond the UK, solely nurses and pharmacists have been granted the authority to prescribe medicines collaboratively (dependently) under a physician's supervision or independently from a limited lists of medicines. ${ }^{4-7}$ The drive 
to extend the medicines prescribing mandate to nonmedical healthcare professionals was related to a variety of aspects within every nation.

In the UK, non-medical prescribing was introduced as part of the National Health Service (NHS) plans, which intended to improve and modernise the healthcare system. ${ }^{8}$ The aim of introducing non-medical prescribing was to enhance patient care and safety, improve patient access and choice of appropriate medicines for their conditions, use the already gained skills of healthcare professionals in the most effective way and promote a more flexible teamwork environment in the NHS. ${ }^{10}$ Pharmacists, nurses, optometrists and allied health professionals can qualify as non-medical prescribers after completing an advanced prescribing training programme. ${ }^{9} 10$ This programme lawfully allows these healthcare professionals to prescribe within their area of competence, such as that pharmacists and nurses can prescribe medicines, appliances and wound dressings as either independent or supplementary prescribers within their clinical area of practice. Some non-medical independent prescriber (NMIPs) are limited to prescribe certain medications within their clinical of specialty, such as optometrists who can only prescribe for eye conditions and surrounding tissues. ${ }^{9}$

Independent prescribing is defined as "prescribing by a practitioner (eg, a doctor, dentist, nurse, or a pharmacist) responsible and accountable for the assessment of patients with undiagnosed or diagnosed conditions and for decisions about the clinical management required, including prescribing. ${ }^{10}$ Whereas, supplementary prescribing is a 'voluntary partnership between the responsible independent prescriber (IP) and a supplementary prescriber, to implement an agreed patient-specific clinical management plan with the patient's agreement, particularly but not only in relation to prescribing for a specific non-acute medical condition or health need affecting the patient'. ${ }^{11}$ Non-medical independent prescribing was introduced in the UK in 2002 after a change in the legislation made by the UK Government allowing the first level registered nurses who have at least 3 years of experience to prescribe independently from a limited list of medicines. ${ }^{10}{ }^{12}$ In 2006, independent prescribing extended for qualified nurses and pharmacists who completed the necessary training to prescribe any medicines within their area of competence with few exceptions. ${ }^{10}$ This was followed by the introduction of optometrist independent prescribing in $2007^{13}$ and, more recently, independent prescribing by allied health professionals including podiatrists and physiotherapists independent prescribing in $2013^{14}$ and therapeutic radiographers independent prescribing in $2016 .{ }^{15}$ The recent healthcare professionals who gained the prescribing authority in Wales were paramedics in 2019. In 2017, the estimated number of NMIPs in the UK was as follows: 30000 nurse IPs; 3000 pharmacist IPs and 600 allied health professionals IPs. ${ }^{16}$ All NMIPs are responsible and accountable for their own prescribing and limiting their prescribing to their therapeutic area of expertise. ${ }^{9}$ Moreover, these healthcare professionals are required to seek appropriate advice or referral if they lack the confidence to manage patients' conditions or prescribe the suitable medicines for their patients. ${ }^{9}$

In Wales, the NHS provides its services via three NHS Trusts and seven health boards (HBs). The seven HBs are Swansea Bay University HB (SBUHB), Cardiff and Vale University HB, Cwm Taf Morgannwg University HB, Hywel Dda University HB (HDUHB), Powys Teaching HB (PTHB), Betsi Cadwaladr University HB (BCUHB) and Aneurin Bevan University HB (ABUHB). The SBUHB was formerly known as Abertawe Bro Morgannwg University HB (ABMUHB), having being renamed in 2019.

Primary healthcare services are the initial point of care for patients in the NHS. In Wales, it has been estimated that around $90 \%$ of people's contact with the NHS is with primary care services, with general practices the main point of contact. ${ }^{17}$ In 2016, there were 441 general practices in Wales and 2009 general practitioners (GPs) (excluding, locums, retainers and registrars). ${ }^{18}$ The Welsh Government and HBs have focused on improving primary care services,${ }^{17}$ and this has included the development of primary care clusters. Clusters comprise groups of adjacent general practices that have linked together to provide advanced medical services locally in order to relieve pressure on hospitals. ${ }^{19}$ The aims of these clusters include improving patients' access to their medicines and information as well as the provision of advice and support to manage medicines. These clusters came into being in the last quarter of $2015 .{ }^{19}$ Currently, there are 64 primary care clusters in Wales that provide services for a population of 30000 to 50000 patients per cluster. ${ }^{19}$ In order to overcome GP shortages, ${ }^{20}{ }^{21}$ these clusters are supported by high numbers of hospital pharmacists, nurses and other professionals. In addition, the Welsh Government and HBs have prioritised funding for new posts and training of other healthcare professionals, such as pharmacist and nurse IPs. ${ }^{17}$ Consequently, the number of non-medical prescribers in primary care has increased in recent years and is expected to rise further. ${ }^{1621}$

Only one published study has investigated the implementation of non-medical prescribing in Wales. ${ }^{16}$ This study aimed to provide an overview of the implementation and utilisation of non-medical prescribing in all healthcare sectors through a national questionnaire survey. The results of this study indicated that the majority of nonmedical prescribers in Wales were based in secondary care settings. Moreover, these researchers stated that the utilisation of non-medical prescribers across Wales, particularly in primary care, was inconsistent and had not been implemented in all services. In addition, it was suggested that there was a need to investigate and recognise the development of primary care services in Wales, with support required for non-medical prescribers. ${ }^{16}$

The aim of this study was to identify the number of NMIPs in Wales and describe their prescribing volume (from April 2011 to March 2018) as a whole, as well as within the seven HBs, before and after the implementation 
of primary care clusters. This is the first study in Wales to use data obtained through a national database to review prescribing volume by NMIPs in primary care. No equivalent studies have been published internationally.

\section{METHODOLOGY}

The study design was a retrospective secondary data analysis of monthly data for prescriptions issued by NMIPs in primary care in Wales and dispensed in community pharmacies, as well as the data on the number of NMIPs within primary care in Wales.

The number of NMIPs who prescribed each month and who prescribed at least one item from April 2011 to March 2018 was obtained through the NHS Wales Shared Services Partnership, Primary Care Services. Prescribing data were obtained from the Comparative Analysis System for Prescribing Audit (CASPA) software system (V.5), provided by the NHS Wales Shared Services. Data were fully anonymised and recorded as part of routine practice; as such, the study did not require ethical approval. CASPA records all dispensed WP10 prescriptions (NHS Welsh prescriptions for use in primary care), to allow financial reimbursement to community pharmacies. ${ }^{9}$ While it is acknowledged that dispensing may not fully reflect prescribing, due to patients not taking their prescriptions to a pharmacy for dispensing, the impact of this is likely to be small. This is due to the prescription charge for people in Wales was abolished in 2007 allowing all patients who were registered with their Welsh GPs to get their prescriptions dispensed from a pharmacy in Wales free of charge. ${ }^{22}$ As a result, the impact of non-dispensed items would have been reduced by this policy, which also limits the financial burden to patients. Therefore, dispensing was used as a surrogate marker for prescribing in this study.

The number of items refers to each single item prescribed by a prescriber on a prescription form to a patient. ${ }^{23}$ All recorded WP10 prescriptions issued by GPs and NMIPs in Wales and dispensed by community pharmacists from April 2011 to March 2018 were extracted and included in the study. The number of prescribed items by NMIPs were extracted from the CASPA system on a monthly basis, and the total number of items per 100000 population (the population data in Wales as a whole and in each HB obtained from the Welsh Government Stats Wales $^{24}$ ) was calculated in order to take the population into consideration. Percentages were calculated for the total number of prescribed items by NMIPs in each HB. The name of ABMUHB was used to illustrate the findings in this $\mathrm{HB}$ as this was its name over the study period.

Although randomised controlled trials are considered the gold standard method to evaluate longitudinal effects of interventions over time,${ }^{25-27}$ they lack the ability to evaluate the already implemented service retrospectively. ${ }^{27}$ Therefore, prescribing trend data were compared before and after the introduction of primary care clusters (the intervention) by using an interrupted time series (ITS) analysis. This analysis was performed using ordinaryleast squares regression with Newey-West SEs and a lag for the autocorrelation structure. The Cumby-Huizinga test for autocorrelation was examined to determine the appropriate autocorrelation structure to be accounted for in the model. The model included preintervention and postintervention trends, as well as a coefficient to examine a change in level immediately postintervention. The parameter estimates are presented alongside $95 \%$ CIs and $p$ values. The counterfactual trend (ie, the trend in the absence of the intervention) was examined, and this was compared with the actual observed trend to calculate absolute and relative differences at the end of the observed period (March 2018). Analysis was performed using the itsa command in Stata V.16.0. ${ }^{28}$ The findings were assumed significant at $\mathrm{p}$ value $<0.05$. CIs were calculated in order to be $95 \%$ certain that the range of values contained the true mean of the data. ${ }^{29}$

The Welsh Government plan ${ }^{17}$ encouraged local HBs to prioritise funding and development of primary care clusters in April 2015. However, the implementation of these clusters is the responsibility of each individual local $\mathrm{HB}$, and there are no definitive time points of their establishment. To accommodate this, the researchers engaged with the relevant stakeholders (eg, policy makers and chief pharmaceutical officer) to determine the appropriate time for the intervention phase. They agreed the intervention phase began 6 months after the provided funding by the government to HBs, meaning October 2015, to allow for an appropriate time for each HB to train NMIPs.

\section{Patient and public involvement}

This research was done without patient and public involvement. Patients were not invited to comment on the study design and were not consulted to develop patient relevant outcomes or interpret the results. Patients were not invited to contribute to the writing or editing of this document for readability or accuracy.

\section{RESULTS}

\section{Trend of the total number of items prescribed by all} prescribers

The total number of items prescribed by all healthcare professionals (GPs and non-medical prescribers) from April 2011 to March 2018 was 540781584 items (17482150 per 100000 population). The total number of prescribed items per 100000 population per year increased by $7.1 \%$ between 2011 and $2012(n=2371511)$ and 2014-2015 ( $\mathrm{n}=2539192)$ and increased by $0.7 \%$ between 2014 and $2015(\mathrm{n}=2539192)$ and 2017-2018 $(\mathrm{n}=2556784)$ (figure 1).

\section{Trend of the total number of items prescribed by NMIPs}

The total number of items prescribed by NMIPs in primary care in Wales between April 2011 and March 2018 was 5088405 items ( $\mathrm{n}=164130$ per 100000 population). 


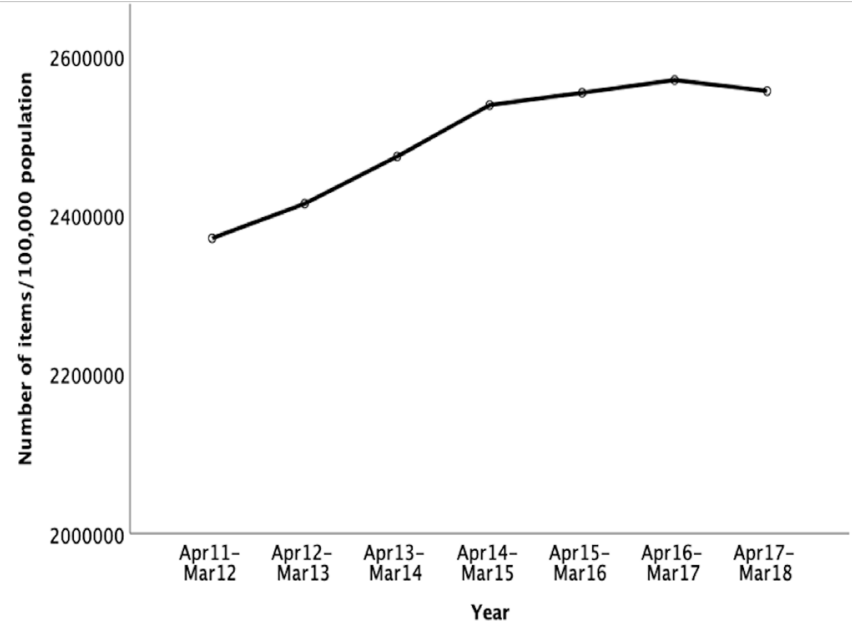

Figure 1 Trend of the total number of items per 100000 population prescribed by all prescribers in primary care in Wales and dispensed in community pharmacies by year.

The number of items prescribed as a percentage of all items prescribed by all healthcare professionals (except items prescribed by dentists) increased from $0.57 \%$ in 2011-2012 to $1.7 \%$ in 2017-2018. As shown in table 1 and figure 2, dispensed prescriptions by NMIPs in primary care started at 31756 and increased on average per month prior to the implementation of primary care clusters by 496 (95\% CI 445 to 548, $\mathrm{p}<0.001)$. There was no evidence to suggest a change in the level immediately following the implementation of primary care clusters in October 2015. However, following this implementation, there was an increase in dispensed prescriptions per month, relative to preimplementation trends, of 1380 on average $(95 \% \mathrm{CI}$ 904 to $1855, \mathrm{p}<0.001)$.

Assuming the preimplementation trend would have continued in the absence of the introduction of primary care clusters, the expected number of dispensed prescriptions by NMIPs at the end of the observation period (March 2018) was 73443 (95\% CI 70260 to 76627), and with the model predicting an expected number (in the presence of primary care clusters) of

Table 1 Parameter estimates from the interrupted time series analysis examining the change in level and slope of dispensed prescriptions in primary care by NMIPs following the implementation of primary care clusters in October 2015 $(\mathrm{n}=84$ months)

\begin{tabular}{lcrrr}
\hline Variable & Coefficient & $\begin{array}{l}\text { Lower } \\
\mathbf{9 5 \%} \mathbf{~ C l}\end{array}$ & $\begin{array}{l}\text { Upper } \\
\mathbf{9 5 \%} \mathbf{C l}\end{array}$ & P value \\
\hline $\begin{array}{l}\text { Intercept } \\
\text { Preintervention }\end{array}$ & 4965.5 & 30208.3 & 33302.8 & $<0.001$ \\
$\begin{array}{l}\text { slope } \\
\text { Level change }\end{array}$ & 3023.4 & -2151.5 & 8198.2 & 0.248 \\
$\begin{array}{l}\text { Postintervention } \\
\text { slope }\end{array}$ & 1379.7 & 904.4 & 1855.1 & $<0.001$ \\
\hline
\end{tabular}

NMIPs, non-medical independent prescribers.

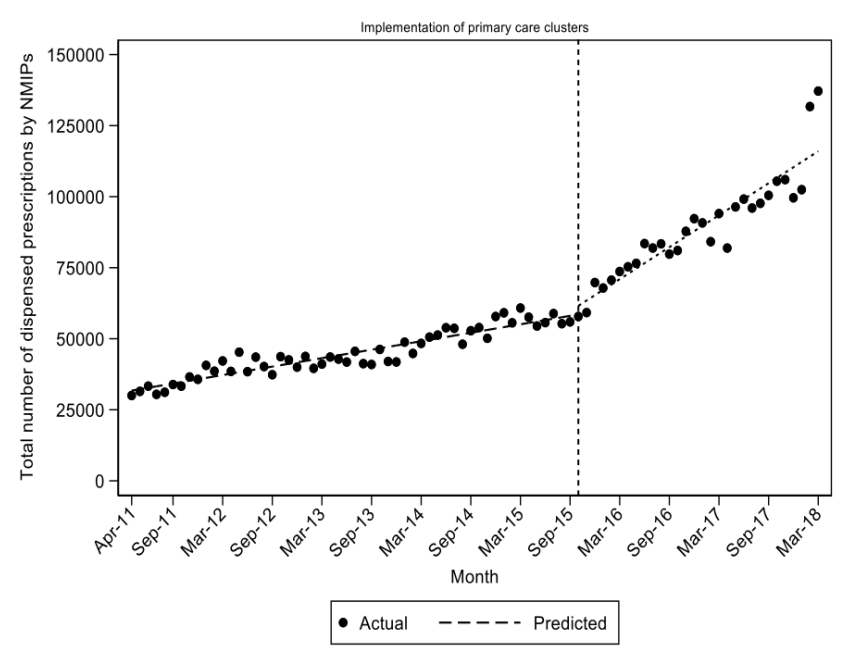

Figure 2 Observed and predicted dispensed prescriptions in primary care by NMIPs prior to and following the implementation of primary care clusters in October 2015 (all Wales). NMIPs, non-medical independent prescriber.

117859 (95\% CI 108049 to 127670 ), there was a $60 \%$ relative increase in the number of dispensed prescriptions by NMIPs following the implementation of primary care clusters over and above what would have been expected in the absence of such a scheme (95\% CI 46 to $75, \mathrm{p}<0.001)$.

\section{The total number of NMIPs}

Data obtained from the NHS Wales Shared Services Partnership shows that the total number of NMIPs who prescribed at least one item from April 2011 to March 2018 was 600 prescribers (474 nurses, 104 pharmacists, 21 physiotherapists and 1 with unknown profession). The total number of NMIPs in each HB is illustrated in figure 3 . The number of prescribing NMIPs per month increased by approximately $140 \%$ between April 2011 $(n=174)$ and March $2018(n=414)$. Of those, the number of nurses increased from 158 in April 2011 to 328 in March 2018 (an increase of 108\%). The number of pharmacists increased from 16 in April 2011 to 68 in March 2018 (an increase of $325 \%$ ), the largest increase was from July $2015(\mathrm{n}=20)$ to March $2018(\mathrm{n}=68)$ by $240 \%$. In January 2015, the first physiotherapist IP started to prescribe with the number increasing to 17 in March 2018.

\section{Trend of the total number of prescribed items by NMIPs in different $\mathrm{HBs}$ preintervention and postintervention}

Table 2 presents the total number of items prescribed by NMIPs, as well as the number per 100000 population and percentage of all items prescribed, per HB. Approximately one-third of the items prescribed by NMIPs was within BCUHB (table 2) with only $4 \%$ in PTHB. Data by HBs are illustrated in figures 4 and 5 , and it can also be seen in the online supplemental file. 


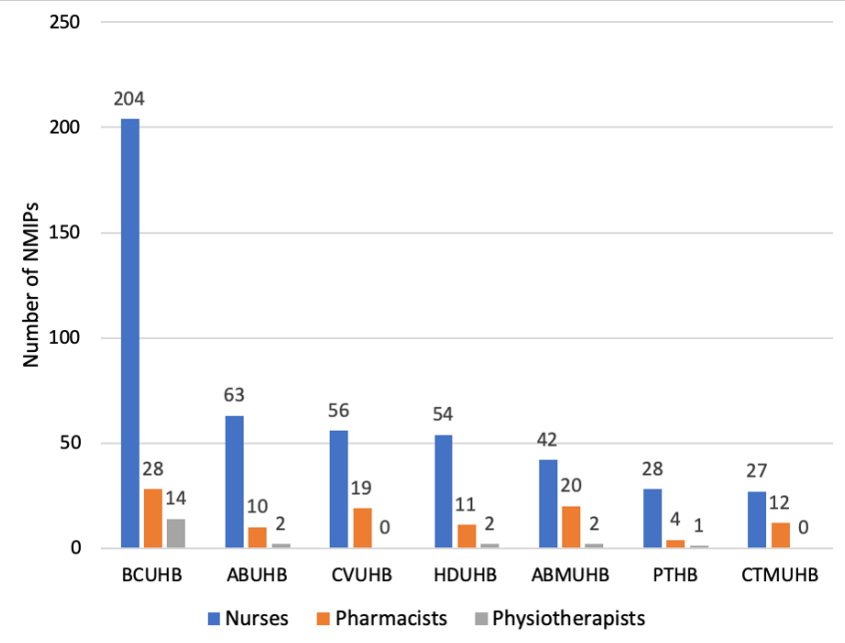

Figure 3 The total number of NMIPs (pharmacists, nurses and physiotherapists) who prescribed at least one item from April 2011 to March 2018 in primary care in Wales in different HBs. ABMUHB, Abertawe Bro Morgannwg University HB; ABUHB, Aneurin Bevan University HB; BCUHB, Betsi Cadwaladr University HB; CTMUHB, Cwm Taf Morgannwg University HB; CVUHB, Cardiff and Vale University HB; HB, health board; HDUHB, Hywel Dda University HB; NMIPs, non-medical independent prescribers; PTHB, Powys Teaching HB.

\section{DISCUSSION}

\section{Statement of the principal findings}

This study investigated the number and associated prescribing volume of NMIPs before and after the implementation of primary care clusters in Wales. The number of NMIPs has increased in primary care in Wales over the study period and the majority of them were nurses, followed by pharmacists and physiotherapists. Interestingly, the database did not identify other healthcare professionals who have prescribing authorisation in Wales, including therapeutic radiographers, chiropodists and podiatrists, and optometrists. ${ }^{16}$

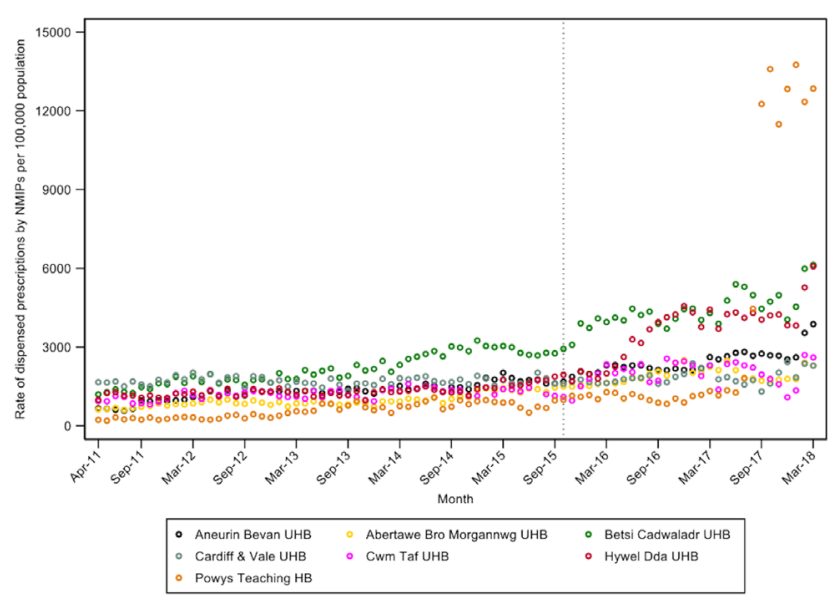

Figure 4 Trend of the total number of dispensed items per 100000 population prescribed by NMIPs in primary care by health board (dashed line denotes introduction of primary care clusters in October 2015). HB, health board; NMIPs, non-medical independent prescribers; UHB, university health board.

The analysis of the prescribed number of items by NMIPs before and after the implementation of primary care clusters showed a $60 \%$ relative increase following the implementation of the primary care clusters in Wales. However, the prescribing of items by NMIPs was inconsistent across the seven HBs.

\section{Strengths and weaknesses}

This is the first study that has used a secondary database analysis, which has provided insights and empirical findings on the prescribing pattern of medicines by NMIPs over time in primary care in Wales. Although this study has achieved its aim and objectives, it has a number of limitations. First, the data provided via the CASPA software system was limited to the last 7 years. Second, this system was designed for financial reimbursement purposes for

Table 2 Total number of items prescribed by NMIPs, as well as the number per 100000 population and percentage of all items prescribed, per $\mathrm{Hb}$ in primary care in Wales and dispensed in community pharmacies since April 2011 until March 2018

\begin{tabular}{lcll}
\hline Health board & $\begin{array}{l}\text { Total number of items } \\
\text { prescribed by NMIPs }\end{array}$ & $\begin{array}{l}\text { \% of the prescribed items by } \\
\text { NMIPs in each HB }\end{array}$ & $\begin{array}{l}\text { Prescribed items by NMIPs per 100000 } \\
\text { population }\end{array}$ \\
\hline BCUHB & 1711949 & 33.64 & 240742.5 \\
ABUHB & 834879 & 16.41 & 139396.5 \\
CVUHB & 711805 & 13.99 & 145069.9 \\
\hline HDUHB & 686166 & 13.48 & 172782.9 \\
\hline ABMUHB & 573624 & 11.27 & 106813.2 \\
CTMUHB & 371315 & 7.30 & 122620.2 \\
\hline PTHB & 198667 & 3.91 & 137000.6 \\
\hline
\end{tabular}

*The percentage of the prescribed items by NMIPs in each HB was calculated based on the total number of items prescribed by NMIPs in all Wales.

ABMUHB, Abertawe Bro Morgannwg University HB; ABUHB, Aneurin Bevan University HB; BCUHB, Betsi Cadwaladr University HB; CTMUHB, Cwm Taf Morgannwg University HB; CVUHB, Cardiff and Vale University HB; HB, health board; HDUHB, Hywel Dda University HB; NMIPs, non-medical independent prescribers; PTHB, Powys Teaching HB. 


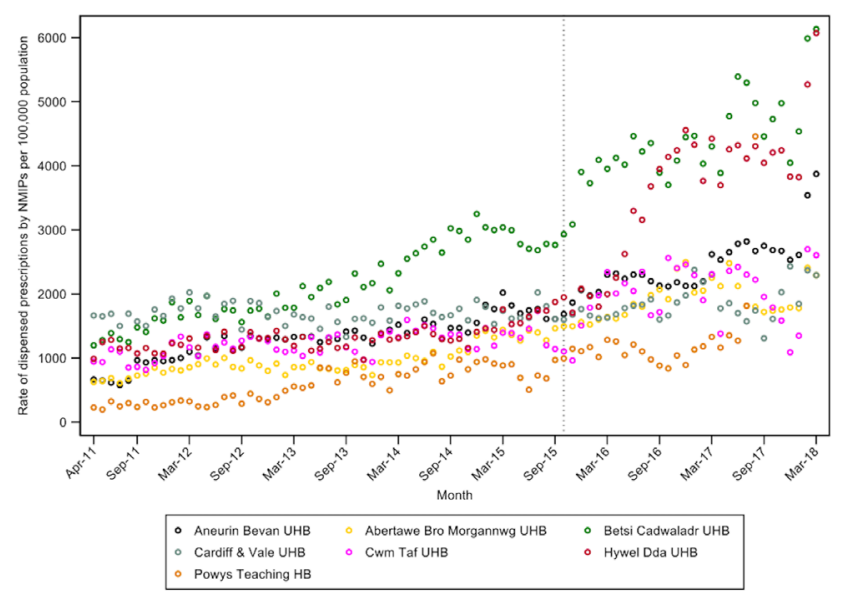

Figure 5 Trend of the total number of dispensed items per 100000 population prescribed by NMIPs in primary care by health board (dashed line denotes introduction of primary care clusters in October 2015). *Final seven outlying data points in Powys Teaching Health Board removed to illustrate trends in other health boards. HB, health board; NMIPs, non-medical independent prescribers; UHB, university health board.

community pharmacies, which means that holding investigations at the level of patients or prescribers, such as stopping or changing patients' medications, as well as clinical safety issues or other prescribing activities, were not possible. In addition, this system only captured NHS prescriptions that were dispensed in community pharmacies. Therefore, prescriptions issued by those prescribers that have not been dispensed as well as private prescriptions that have been prescribed by NMIPs, such as optometrists, were not captured by the system. Finally, the professions of NMIPs as pharmacist, nurse, physiotherapist or other were not identified on the prescriptions and, consequently, in the CASPA system. The ITS analysis may have the limitation of the presence of unknown confounding variables, which are outside of the researcher's control, that may have happened at the same time of the intervention, and this leads to the difficulty of establishing causal effects. ${ }^{30}$ However, this analysis has the strength of evaluating data at the whole population level, ${ }^{31}$ which allowed the researchers to evaluate the utilisation of NMIPs in primary care across all of Wales.

\section{Comparison with other studies}

The increase in the number of NMIPs in primary care in Wales may suggest that the primary care sector has recognised the skills of these practitioners, improving the skill-mix in this sector, and hopefully reducing the pressure on GPs, that is, the benefits described in the second Crown Report. ${ }^{32}$ Since the last quarter of 2015, the increase in the percentage of pharmacist IPs was higher than the increase in the percentage of nurse IPs $(325 \%$ vs $108 \%)$. This could be explained by the implementation of the Welsh Government Plan, ${ }^{17}$ introduction of primary care clusters ${ }^{19}$ and the shortage of GPs in
Wales, particularly in BCUHB. ${ }^{152-34}$ All of these factors may have contributed to recruitment of more pharmacist IPs. ${ }^{17}$ Pharmacist independent prescribing is a new role for pharmacists within clusters, with many secondary care based pharmacist IPs moving into these positions. ${ }^{21}$ This may lead to a shortage of pharmacists within secondary care and has highlighted the need for a pharmacy workforce plan for Wales.

Although the number of nurse IPs is much greater than pharmacist IPs, they only represent $5 \%$ of the nursing workforce, ${ }^{35}$ while pharmacist IPs represent $7 \%$ of the pharmacist profession. ${ }^{36}$ The fact that there are more nurse IPs than other professions is in line with the findings of other studies that have investigated the implementation of non-medical prescribing in England ${ }^{33} 37$ and Wales. ${ }^{16}$ Therapeutic radiographer IPs are based within secondary or tertiary care settings in Wales and therefore, they would be unlikely to be included in the database. However, the other professions, such as chiropodists, podiatrists and optometrists, could potentially be working in primary care settings but do not appear to have issued NHS prescriptions as they could have been prescribing medications for their patients within private hospitals, at point of care or not using their prescribing qualification. If they were not using their prescribing qualification, this may suggest that HBs need to investigate the reasons for that in order to prevent wasting the time and expenses incurred for training and failure to deliver an improved service to patients.

The increase in the number of NMIPs, particularly pharmacist IPs, may explain the increased rate of prescribing of medicines by these practitioners over the same period. The high number of prescribed items by NMIPs in BCUHB (34\%) compared with other HBs could be explained by the high number of NMIPs in BCUHB (246 NMIPs). It is evident that the utilisation of NMIPs is inconsistent across the seven HBs in Wales, which supports previous research. ${ }^{16}$ BCUHB and HDUHB represent the largest geographical areas in Wales compared with other $\mathrm{HBs}^{38}$ but have the lowest number of GPs per 10000 population (6.1 and 5.8, respectively). ${ }^{39}$ The low number of GPs in these HBs could be related to issues of recruitment, as well as the difficulty in keeping those who are already employed in their positions. ${ }^{34} 40$ The shortage of GPs in these HBs may explain the early adoption of non-medical independent prescribing. Although PTHB showed the lowest number of items prescribed by NMIPs over the study period, it is the smallest geographical area in Wales with the lowest population compared with other HBs. An equivalent increase in the number of prescribers and items would therefore produce a bigger percentage change than in a larger HB. However, the large increase in the trend of the prescribing items in this HB over the last 2 years of the study period may be explained by the increase in the number of NMIPs. Moreover, PTHB only has primary care services, so while other HBs may have been training IPs in both primary and secondary care settings, the focus in PTHB would have been primary 
care only, which may have resulted in a greater change. However, due to the nature of the database used, it was not possible to investigate this further, and this could be the focus of future work.

\section{The meaning of the study: possible explanations and implications for clinicians and policy makers}

The findings of this study showed inconsistency in terms of the implementation of the NMIPs' services between HBs in primary care in Wales, particularly after the primary care clusters' implementation. Although there is a lack of evidence with regards to the reasons and barriers behind this, some reasons that may have contributed to lower utilisation of this service in some HBs may include the lack of funding ${ }^{16374142}$ and lack of a plan or strategy to develop this service. ${ }^{37}$ However, these studies are outdated given the pace of change. Moreover, it has not been conducted in Wales in particular, which may not reflect recent practice and policies in this country. Due to the lack of evidence regarding the impact of these barriers on the implementation of non-medical independent prescribing in each $\mathrm{HB}$, further research is required to investigate this matter. This study provides the initial evidence for such research, as well as providing the opportunity to share learning among HBs.

\section{Unanswered questions and future studies}

This study provides a research agenda for further investigation to examine questions related to efficiency, quality of prescribing, cost-effectiveness and improved access to services provided by NMIPs. With the presence of some variety and inconsistency in the prescribing trend of NMIPs across different HBs, this provides an opportunity to share the knowledge on advanced and novel services provided by these prescribers as well as to investigate the reasons behind it.

\section{CONCLUSION}

The number of NMIPs and their prescribing trends of medicines increased in Wales in general, as well as in the majority of HBs, particularly the number of pharmacist IPs, since the implementation of primary care clusters. This could be related to the implementation of the Welsh Government Plan ${ }^{17}$ and the introduction of primary care clusters. The findings of this study may suggest that the increased number of NMIPs in the primary care sector in Wales over time may help to reduce the pressure on GPs and improve the skill-mix across different therapeutic areas. This aligns with the main reasons for the implementation of non-medical prescribing in the UK, as outlined in the second Crown Report. ${ }^{32}$ Future studies should focus on efficiency and quality of prescribing by NMIPs in primary care.

\section{Author affiliations}

${ }^{1}$ School of Pharmacy and Pharmaceutical Sciences, Cardiff University, Cardiff, UK ${ }^{2}$ All Wales Therapeutics and Toxicology Centre, Academic Centre, University Hospital Llandough, Cardiff, UK
${ }^{3}$ School of Care Sciences, University of South Wales - Trefforest Campus, Treforest, UK

${ }^{4}$ Centre for Trials Research, University of Cardiff, Cardiff, UK

${ }^{5}$ School of Healthcare Sciences, College of Biomedical and Life Sciences, Cardiff University, Cardiff, UK

\section{Twitter Karen Hodson @HodsonKL}

Acknowledgements We would like to thank All Wales Therapeutics and Toxicology Centre in Cardiff who granted the permission for the team to access the Comparative Analysis System for Prescribing Audit (CASPA) system and extract the data. Moreover, we are grateful to Taif University and the Government of Saudi Arabia represented by the Saudi Arabian Cultural Bureau in the UK for supporting the lead author in order to conduct this project as a part of his $\mathrm{PhD}$ project.

Contributors SSAA made a substantial contribution to the conception and design of the work; the acquisition, analysis and interpretation of data; and drafting of the work. RD and KarH made a substantial contribution to the design of the work, acquisition, analysis and interpretation of data. PD made a substantial contribution to data acquisition, analysis and interpretation. KatH made a substantial contribution to the data acquisition and interpretation of data. DG made a substantial contribution to data analysis and interpretation. MC made a substantial contribution to the design of the work and interpretation of data. EH made a substantial contribution to data analysis and interpretation. All authors critically revised drafts of the work and approved the final version to be published and agree to be accountable for all aspects of the work in ensuring that questions related to the accuracy or integrity of any part of the work are appropriately investigated and resolved.

Funding The authors have not declared a specific grant for this research from any funding agency in the public, commercial or not-for-profit sectors.

Competing interests None declared.

Patient consent for publication Not required.

Provenance and peer review Not commissioned; externally peer reviewed.

Data availability statement All data relevant to the study are included in the article or uploaded as supplemental information. No additional data available.

Supplemental material This content has been supplied by the author(s). It has not been vetted by BMJ Publishing Group Limited (BMJ) and may not have been peer-reviewed. Any opinions or recommendations discussed are solely those of the author(s) and are not endorsed by BMJ. BMJ disclaims all liability and responsibility arising from any reliance placed on the content. Where the content includes any translated material, BMJ does not warrant the accuracy and reliability of the translations (including but not limited to local regulations, clinical guidelines, terminology, drug names and drug dosages), and is not responsible for any error and/or omissions arising from translation and adaptation or otherwise.

Open access This is an open access article distributed in accordance with the Creative Commons Attribution Non Commercial (CC BY-NC 4.0) license, which permits others to distribute, remix, adapt, build upon this work non-commercially, and license their derivative works on different terms, provided the original work is properly cited, appropriate credit is given, any changes made indicated, and the use is non-commercial. See: http://creativecommons.org/licenses/by-nc/4.0/.

ORCID iD

Saeed Saad A Alghamdi http://orcid.org/0000-0002-7144-7016

\section{REFERENCES}

1 Department of Health. Medicines act 1968. DOH: London, 1968. http://www.legislation.gov.uk/ukpga/1968/67

2 Craig EJ. A review of prescriptive authority for nurse practitioners. $J$ Perinat Neonatal Nurs 1996;10:29-35.

3 Kroezen M, van Dijk L, Groenewegen PP, et al. Nurse prescribing of medicines in Western European and Anglo-Saxon countries: a systematic review of the literature. BMC Health Serv Res 2011;11:127.

4 McBane S, Dopp A, Abe A, et al. Collaborative drug therapy management and comprehensive medication Management-2015 pharmacotherapy. J Human Pharm Drug Therapy 2015;35:e39-50.

5 Alberta College of Pharmacists. Guide to receiving additional prescribing authorization. 2nd edn. Alberta, 2013. https:// pharmacists.ab.ca/sites/default/files/APAGuide.pdf 
6 Raghunandan R, Tordoff J, Smith A. Non-medical prescribing in New Zealand: an overview of prescribing rights, service delivery models and training. Ther Adv Drug Saf 2017;8:349-60.

7 Dunn SV, Cashin A, Buckley T, et al. Nurse practitioner prescribing practice in Australia. J Am Acad Nurse Pract 2010;22:150-5.

8 Department of Health. The NHS plan: a plan for investment. A plan for reform. DOH: London, 2000. http://webarchive.nationalarchives. gov.uk/20130124064356/http://www.dh.gov.uk/prod_consum_dh/ groups/dh_digitalassets/@dh/@en/@ps/documents/digitalasset/dh_ 118522.pdf

9 Welsh Government. Non-Medical prescribing in Wales, guidance. Cardiff: Welsh Government, 2017. http://www.awmsg.org/docs/ awmsg/

10 Department of Health. Improving patients' access to medicines: A guide to implementing nurse and pharmacist independent prescribing within the NHS in England. London: DoH, 2006. http:// webarchive.nationalarchives.gov.uk/

11 Medicines Control Agency (MCA). Proposals for supplementary prescribing by nurses and pharmacists and proposed amendments to the prescription only medicines (human use) order 1997. London: MCA: MLX 284, 2002. Available: http://www.mhra.gov.uk/home/ groups/comms-ic/documents/websiteresources/con2022567.pdf [Accessed 8 Jul 2019].

12 Department of Health. Extending independent nurse prescribing within the NHS in England: a guide for implementation. London: $\mathrm{DOH}, 2002$.

13 Department of Health. Optometrists to get independent prescribing rights. London: $\mathrm{DOH}, 2007$.

14 Department of Health. The medicines act 1968 and the human medicines regulations (Amendment) order. London: DOH, 2013. http://www.legislation.gov.uk/uksi/2013/1855/pdfs/uksi_20131855 en.pdf

15 National Health Service (NHS) England. Allied health professions medicines project. London: NHS England, 2016. https://www. england.nhs.uk/ahp/med-project/

16 Courtenay M, Khanfer R, Harries-Huntly G, et al. Overview of the uptake and implementation of non-medical prescribing in Wales: a national survey. BMJ Open 2017;7:e015313.

17 Welsh Government. Our plan for a primary care service for Wales up to March 2018. NHS Wales, 2015. http://www.cpwales.org.uk/ getattachment/The-Health-Landscape/NHS-Wales-Primary-CareStrategy/150218primaryen-pdf0-(Updated-March-2015).pdf.aspx? lang=en-GB

18 Wales Audit Office. A picture of primary care in Wales [online] Auditor General for Wales, 2018. Available: http://www.assembly.wales/laid\% 20documents/agr-Id11520/agr-ld11520-e.pdf [Accessed 8 Jul 2019].

19 The National Assembly for Wales. Inquiry into primary care: clusters. Cardiff: Health, Social Care and Sport Committee, 2017. http://www. assembly.wales/laid\%20documents/cr-ld11226/cr-ld11226-e.pdf

20 Royal Pharmaceutical Society Wales. Your care, your medicines: pharmacy at the heart of patient-centered care, 2015. Available: https://www.rpharms.com/Portals/0/RPS\%20document\% 20library/Open\%20access/Publications/Your\%20Care\%20Your\% 20Medicines\%20report.pdf [Accessed 8 Jul 2019].

21 Hodson K, Deslandes R, Courtenay M. Pharmacist independent prescribers can make a significant contribution to antimicrobial stewardship. Pharmaceutical J 2017.

22 The Welsh Government. Free prescriptions and charges for drugs and appliances (Wales) Regulations [online], 2007. Available: http:// www.legislation.gov.uk/wsi/2007/121/made [Accessed 24 Apr 2020].

$23 \mathrm{NHS}$, the Information Centre for Health and Social Care. Prescribing and primary care services, prescribing measures and their application. Leeds: Health and Social Care Information Centre, 2012. https://webarchive.nationalarchives.gov.uk/20180307194416/http:// content.digital.nhs.uk/media/10952/Prescribing-Measures/pdf/ CHttpHandler.pdf
24 Welsh Government. Population estimates by local health boards and age [online], 2018. Available: https://statswales.gov.wales/Catalogue/ Population-and-Migration/Population/Estimates/Local-HealthBoards/populationestimates-by-lhb-age [Accessed 12 Apr 2020].

25 Campbell M, Fitzpatrick R, Haines A, et al. Framework for design and evaluation of complex interventions to improve health. BMJ 2000;321:694-6.

26 Victora CG, Habicht J-P, Bryce J. Evidence-Based public health: moving beyond randomized trials. Am J Public Health 2004; $94: 400-5$

27 Bonell CP, Hargreaves J, Cousens S, et al. Alternatives to randomisation in the evaluation of public health interventions: design challenges and solutions. $J$ Epidemiol Community Health 2011;65:582-7.

28 Linden A. Conducting interrupted time-series analysis for single- and multiple-group comparisons. Stata J 2015;15:480-500.

29 Field A. Discovering statistics using IBM SPSS statistics. 5th edn. Los Angeles: Sage edge, 2018.

30 Ramsay CR, Matowe L, Grilli R, et al. Interrupted time series designs in health technology assessment: lessons from two systematic reviews of behavior change strategies. Int $J$ Technol Assess Health Care 2003;19:613-23.

31 Bernal JL, Cummins S, Gasparrini A. Interrupted time series regression for the evaluation of public health interventions: a tutorial. Int J Epidemiol 2016;46:348-55.

32 Department of Health. Review of prescribing, supply and administration of medicines. Final report (crown II report). London: $\mathrm{DOH}, 1999$.

33 Courtenay M, Carey N, Stenner K. An overiew of non medical prescribing across one strategic health authority: a questionnaire survey. BMC Health Serv Res 2012;12:138.

34 Brennan S. North Wales facing GP 'recruitment crisis' leading doctor warns [online], 2017. Available: https://www.dailypost.co.uk/news/ north-wales-news/gp-surgeries-recruitment-crisis-jessup-13453024 [Accessed 8 Jul 2019].

35 Courtenay M. An overview of developments in nurse prescribing in the UK. Nurs Stand 2018;33:40-4.

36 GPhC (General Pharmaceutical Council). Prescribers survey report. London, 2016. Available: https://www.pharmacyregulation.org/sites/ default/files/gphc_prescribers_survey_report.pdf [Accessed 8 Jul 2019].

37 Latter S, Blenkinsopp A, Smit A, et al. Evaluation of nurse and pharmacist independent prescribing. Department of health policy research programme project 0160108 (October 2010): University of Southampton and Keele university, 2011. Available: https://eprints. soton.ac.uk/184777/3/ENPIPfullreport.pdf [Accessed 8 Jul 2019].

38 Wales NHS. Public Health Wales Observatory / Wales and its Local Health Boards: Demography Profile [online], 2017. Available: http:// www.publichealthwalesobservatory.wales.nhs.uk/wales-local-healthboards-demography-profile [Accessed 2 May 2019].

39 Welsh Government. Local health board comparisons of GP workforce by year, 2018. Available: https://statswales.gov.wales/ Catalogue/Health-and-Social-Care/General-Medical-Services/loca Ihealthboardcomparisonsofgpworkforce-by-year [Accessed 2 May 2019].

40 Jones M. More than 8,000 people will be served by just three GPs as another North Wales surgery closes [online] Daily Post Wales, 2017. Available: https://www.dailypost.co.uk/news/more-8000-peopleserved-just-13905020 [Accessed 8 Jul 2019].

41 Cooper RJ, Anderson C, Avery T, et al. Nurse and pharmacist supplementary prescribing in the UK-a thematic review of the literature. Health Policy 2008;85:277-92.

42 Hacking S, Taylor J. An evaluation of the scope and practice of non-medical prescribing in the North West for NHS North West. Lancashire: NHS North West, 2010. https://www.researchgate.net/ profile/Suzanne_Hacking/publication/ 